\title{
RMetS
}

\section{Analytical description of a nocturnal low-level jet}

\author{
Alan Shapiro ${ }^{\mathrm{a}, \mathrm{b} \star}$ and Evgeni Fedorovich ${ }^{\mathrm{a}}$ \\ ${ }^{a}$ School of Meteorology, University of Oklahoma, Norman, Oklahoma, USA \\ ${ }^{\mathrm{b}}$ Center for Analysis and Prediction of Storms, University of Oklahoma, Norman, Oklahoma, USA \\ ${ }^{*}$ Correspondence to: Alan Shapiro, School of Meteorology, University of Oklahoma, 120 David L. Boren Blvd., room \\ 5900, Norman, OK 73072, USA. E-mail: ashapiro@ou.edu
}

\begin{abstract}
An exact analytical solution of the equations of motion is presented for the Blackadar conceptual model of the nocturnal low-level jet as an inertial oscillation arising from the sudden release of frictional constraint (near-cessation of dry-convective turbulent mixing) near sunset. The jet is modelled as a transient one-dimensional boundary-layer phenomenon, with the release of frictional constraint emulated by an impulsively reduced mixing coefficient (eddy viscosity). Prior to the reduction, the flow is in an equilibrium state described by the classical steady-state Ekman solution. The dimensional parameters of the transient problem are the Coriolis parameter, the post- and pre-sunset eddy viscosities, and an imposed pressure gradient force. The corresponding non-dimensional problem is governed by a single parameter, the ratio of the post- and pre-sunset mixing coefficients. The solution is obtained by the method of Laplace transforms. Copyright (c) 2010 Royal Meteorological Society
\end{abstract}

Key Words: atmospheric boundary layer; inertial oscillation; analytical model

Received 6 July 2009; Revised 18 February 2010; Accepted 2 March 2010; Published online in Wiley InterScience 4 May 2010

Citation: Shapiro A, Fedorovich E. 2010. Analytical description of a nocturnal low-level jet. Q. J. R. Meteorol. Soc. 136: 1255-1262. DOI:10.1002/qj.628

\section{Introduction}

The nocturnal low-level jet is an atmospheric boundary-layer phenomenon most extensively documented over the Great Plains of the United States (e.g. Blackadar, 1957; Hoecker, 1963; Bonner, 1968; Parish et al., 1988; Mitchell et al., 1995; Stensrud, 1996; Zhong et al., 1996; Whiteman et al., 1997; Banta et al., 2002; Song et al., 2005; Banta, 2008; Walters et al., 2008) but also observed at many other locations worldwide (see references in Sládkovič and Kanter, 1977; Stensrud, 1996; Beyrich et al., 1997). The jet typically begins to develop around sunset, under dry cloud-free conditions conducive to strong radiational cooling, reaches a peak intensity in the early morning hours, and then decays shortly after dawn, with the onset of daytime convective mixing. It is characterized by an anticyclonic turning of the wind vector with time, and the development of a pronounced wind maximum typically at levels less than $1 \mathrm{~km}$ above ground level, and frequently at levels less than $500 \mathrm{~m}$ above ground level. The peak jet winds are often supergeostrophic by $70 \%$ or even more.

As discussed in Stensrud (1996) and Shapiro and Fedorovich (2009), nocturnal low-level jets exert significant influence on weather and regional climate. The jets provide dynamical and thermodynamical support for the development of deep convective storms and heavy rain events, they can transport lower-tropospheric air pollutants hundreds of miles over the course of a night, they affect the seasonal dispersal of fungi, pollens, spores and migrating insects, and they are an important source of energy for the wind-energy industry. Strong wind shear associated with low-level jets is an aviation hazard.

Several theories have been advanced for the dynamical origin of these jets. Blackadar (1957) described the nocturnal jet as an inertial oscillation that develops over flat terrain in response to the rapid stabilization of the boundary layer that occurs near sunset under relatively dry, cloud-free conditions (the characteristics of the daytime convective boundary layer, nocturnal boundary layer, and the evening transition are summarized in Stull (1988) and Sorbjan (1989)). The process of jet formation can be explained with the aid of a schematic hodograph diagram (Figure 1). During the day, the flow is considered to be in an equilibrium state, with the horizontal pressure gradient force, Coriolis force and frictional force (turbulent stress) balancing each other. The daytime wind for a site in the Northern Hemisphere 


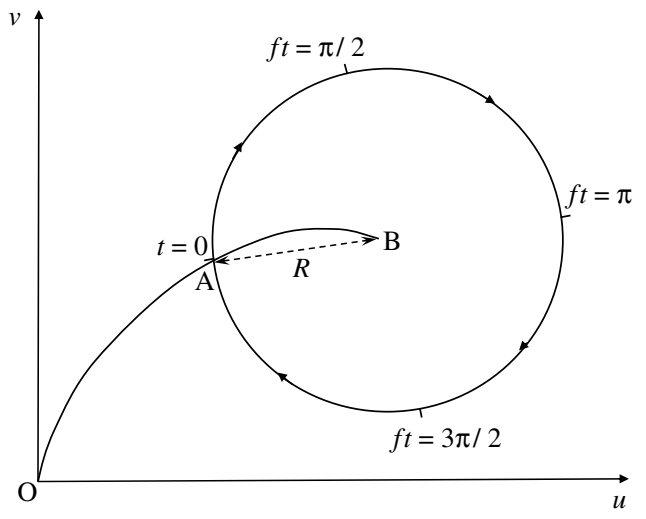

Figure 1. Schematic of an air parcel's Cartesian $(u, v)$ velocity components in a Northern Hemisphere inertial oscillation (adapted from Blackadar, 1957). Curve OAB is the initial $(t=0)$ hodograph, roughly at the time of sunset. Point $\mathrm{O}$ is at ground level. Point B is at the top of boundary layer, where the flow is considered to be geostrophic. Point A is an arbitrary location on the initial hodograph. An air parcel released from the frictional constraint at $t=0$ undergoes an inertial oscillation, manifested on the hodograph plane as a circle with radius $R$ equal to the magnitude of the parcel's initial ageostrophic wind speed.

is represented on Figure 1 by a curve $(\mathrm{OAB})$ that turns anticyclonically with height from the ground (point $\mathrm{O}$ ) to the top of the boundary layer (point B), where frictional effects are minimal and the flow is nearly geostrophic. If skies are clear and the air is dry, radiational cooling and the change of sign of the heat transfer from the ground near the time of sunset $(t=0)$ result in a rapid decay of the vertical mixing in the boundary layer. Freed of a frictional constraint, air parcels accelerate under the resulting force imbalance. The inviscid solution for the subsequent motion is represented on the hodograph plane by a circle whose radius $R$ is the distance of a point on the initial hodograph (point A) from the geostrophic point B. In other words, the amplitude of the oscillation (radius $R$ ) is proportional to the initial ageostrophic wind speed. Accordingly, the oscillation amplitude is expected to grow as the ground is approached until the frictional force, which inevitably becomes important near the ground, becomes large enough. The period of the oscillation is $2 \pi / f$, where $f$ is the Coriolis parameter.

Although not explicitly included in the original Blackadar theory (1957), frictional stress was included in the follow-up study by Buajitti and Blackadar (1957), with a variety of time and height variations considered for the eddy viscosity (mixing coefficient). However, most of the eddy viscosities considered in that study evolved gradually (single frequency, $24 \mathrm{~h}$ period) and did not emulate the more rapid changes expected during the evening transition period (Fig. 1 of Staley, 1956; Fig. 22 of Yamada and Mellor, 1975; Fig. 5 of Hong et al., 2006). Although one eddy viscosity in the Buajitti and Blackadar study did change more rapidly - as a piecewise linear function of time - the very coarse vertical grid used in the numerical solution was not generally suited to resolve a boundary-layer-like response, in terms of the low elevation of wind maximum, shallowness of the layer of supergeostrophic winds, and intensity of peak winds. Sheih (1972) obtained an exact analytical solution for the case of a gradually varying (single-frequency, $24 \mathrm{~h}$ period) spatially constant eddy viscosity, the same problem for which Buajitti and Blackadar (1957, section 2) obtained an approximate analytical solution. Thorpe and Guymer (1977), Beyrich and
Klose (1988), and Singh et al. (1993) further modified the one-dimensional Blackadar theory of the nocturnal low-level jet by considering a variety of stress parametrizations, though with various structural or dynamical features treated as vertically discontinuous, slab-like or layered. Wippermann (1973), Delage (1974), Brook (1985), and Davies (2000) extended the Blackadar conceptual model by incorporating vertically continuous (apart from numerical discretization) turbulent stress parametrizations in their one-dimensional planetary boundary layer models. Recent advances in computer technology are making large-eddy simulation (LES) of the Blackadar jet scenario increasingly feasible, with some simulations extending over the daytime dry convective regime, the evening transition period, and the nocturnal period during which the jet develops. An LES of the stably stratified atmospheric boundary layer over flat terrain with imposed horizontal pressure gradient force evolving from an initial daytime dry convective state (Saiki et al., 2000) and of an atmospheric boundary layer over flat terrain evolving over the course of a full diurnal cycle with imposed horizontal pressure gradient force (Kumar et al., 2006) produced Blackadar-like inertial oscillations and associated low-level jets. An LES of a full diurnal cycle over flat terrain initialized with morning sounding data from day 33 of the Wangara field experiment and forced with observed time-dependent geostrophic wind profiles (Basu et al., 2008) closely reproduced the structure of the observed low-level jet.

Another class of theories has focused on the effect of terrain-associated baroclinicity on the structure and geographical preference of the Great Plains nocturnal jet, that is, the high frequency of jet formation over the sloping terrain of the Great Plains (peak around $100^{\circ} \mathrm{W}$ ) rather than over the flatter terrain further east. Holton (1967) studied the response of the boundary layer over a sloping surface to a gradually varying (single frequency, $24 \mathrm{~h}$ period) and deep volumetric heating/cooling function. The mixing coefficients for heat and momentum were treated as spatially and temporally constant. Although a diurnal wind oscillation could be induced by the heating function, Holton's results did not correctly reproduce the observed phase of the diurnal oscillations, and arguably the flow was not as jet-like as observations show. Bonner and Paegle (1970) considered a gradually varying (single-frequency, $24 \mathrm{~h}$ period) eddy viscosity and geostrophic wind, with the periodicity of the geostrophic wind ascribed to the diurnal temperature cycle over sloping terrain. Their results were in reasonable agreement with observations, but the amplitude of the oscillation was sensitive to the magnitude of the geostrophic wind, the choice of eddy viscosity, and the phase difference between variations of the eddy viscosity and the geostrophic wind. Shapiro and Fedorovich (2009) extended the Blackadar (1957) inviscid theory to include terrain slope and ambient stratification. In their study the Great Plains low-level jet was modelled analytically as an inertial-gravity oscillation induced by the sudden release of frictional constraint near sunset. The theory predicted that jet hodographs associated with a southerly geostrophic wind and terrain that slopes down towards the east should be slightly elliptical with major axis in the east/west direction, in agreement with case-studies and climatological analyses of the Great Plains low-level jet. The theory provided a physical mechanism for flow over the slope to develop a jet-like velocity profile from a well-mixed (uniform) initial 
velocity field, and predicted the existence of an optimum slope angle associated with peak jet strength - a result also consistent with climatological studies. However, that agreement could only be regarded as qualitative, since the optimum slope angle predicted in the more realistic of the considered scenarios would be associated with terrain further west than implied by climatology. Terrain-associated baroclinicity likely also affects low-level jets in other areas of the world (e.g. Saulo et al., 2004; Zhang et al., 2006; Cuxart and Jiménez, 2007), as does baroclinicity associated with land/sea temperature contrasts (e.g. Zemba and Friehe, 1987; Karipot et al., 2009).

The Blackadar prediction of a low-level jet with a wind vector that veers in time with peak winds attained in the early morning hours has been confirmed qualitatively in many studies. Although quantitative analyses suggest that the theory may be incomplete or in some cases the effects may be of secondary importance (see discussion in section 1 of Shapiro and Fedorovich (2009)), many investigators have concluded that their low-level jet observations are consistent with the Blackadar inertialoscillation mechanism. Accordingly, the Blackadar inertialoscillation theory remains one of the most cited theories in boundary-layer meteorology. The purpose of the present paper is to report on a vertically continuous analytical solution of the equations of motion for one of the most basic Blackadar-like flow scenarios - the response of a frictional equilibrium (Ekman) flow to a sudden reduction of eddy viscosity. To the authors' knowledge, this is the first vertically continuous analytical description of this flow scenario.

As in the classical Ekman solution, we consider a spatially constant eddy viscosity, flat terrain, and a spatially and temporally constant geostrophic wind (Pedlosky, 1987; Stull, 1988). Since the analytical solution explicitly displays the governing parameter dependencies, it could potentially be used to help parametrize frictionally induced inertial oscillations in numerical models of contaminant dispersal. However, due to the highly idealized nature of our approach, the solution will probably be more of interest as an educational device for a conceptual description of a historically and practically important flow type. The simple theory considered herein bridges a gap in complexity between the original inviscid Blackadar conception of lowlevel jets over flat terrain and the more sophisticated numerical model treatments.

\section{Governing equations}

The simplest model of turbulent stress in geophysical boundary layers is based on the hypothesis that momentum transport by turbulent eddies can be parametrized through a turbulent (eddy) viscosity acting on a mean field of momentum in a manner analogous to molecular diffusion (Ekman, 1905). The eddy-viscosity concept has led to useful qualitative descriptions of a variety of turbulent geophysical flows including atmospheric Ekman layers (Clarke, 1970; Houghton, 1977; Lettau, 1983), oceanic Ekman layers (Price et al., 1987; Chereskin, 1995; Ralph and Niiler, 1999), sea breezes (Walsh, 1974; Sun and Orlanski, 1981), and anabatic and katabatic flows (Defant, 1949; Egger, 1981; Kondo, 1984; Papadopoulos et al., 1997; Oerlemans, 1998). However, despite the successes of some appropriately tuned models based on the eddy-viscosity concept, it should always be borne in mind that eddy viscosity is a rather ad hoc concept. As noted by Pedlosky (1987, p 46), the notion of eddy viscosity is '.. at best, an empirical concept - hard to justify, even harder to quantify, and impossible to derive rigorously.'

We consider the transient solution arising from an impulsive change in eddy viscosity, designed to emulate, albeit crudely, the sudden reduction in frictional stress associated with the evening transition. By working with a greatly reduced (but non-zero) post-sunset eddy viscosity, the shallow boundary-layer nature of the inertial oscillation emerges as part of the solution; there is no explicit specification of a boundary-layer depth. With the eddy viscosity treated as spatially constant, a fully analytical vertically continuous solution of the equations of motion corresponding to the original Blackadar low-level jet scenario is obtained.

We consider the standard one-dimensional equations of motion used to describe homogeneous viscous incompressible pressure-driven Ekman flow on an $f$-plane (Pedlosky, 1987; Stull, 1988). For the sake of definiteness, we restrict attention to the Northern Hemisphere $(f>0)$. The flow is considered to be in a geostrophic balance far above the ground $(z \rightarrow \infty)$. This balance is disrupted near the surface by a frictional force, which we parametrize in constant eddy-viscosity terms. In a right-hand Cartesian coordinate system, in which the $x$-axis is aligned with the geostrophic wind vector $\mathbf{u}_{\mathrm{g}}$, and the $y$-axis cuts across isobars at right angles towards low pressure, the governing equations for the problem become

$$
\begin{aligned}
& \frac{\partial u}{\partial t}=f v+K \frac{\partial^{2} u}{\partial z^{2}}, \\
& \frac{\partial v}{\partial t}=-f\left(u-u_{\mathrm{g}}\right)+K \frac{\partial^{2} v}{\partial z^{2}}
\end{aligned}
$$

where $u_{\mathrm{g}} \equiv\left|\mathbf{u}_{\mathrm{g}}\right|$ is the geostrophic wind speed, $u(z, t)$, $v(z, t)$ are the wind components in the $x$ and $y$ directions, respectively, $K$ is the eddy-viscosity coefficient, and $z$ is height. We solve these equations subject to no-slip conditions at ground level $(z=0)$,

$$
u(0, t)=0, \quad v(0, t)=0,
$$

and pure geostrophic flow aloft,

$$
\lim _{z \rightarrow \infty} u(z, t)=u_{\mathrm{g}}, \quad \lim _{z \rightarrow \infty} v(z, t)=0
$$

The initial (sunset) velocity components $u_{0}(z), v_{0}(z)$, are obtained from the steady-state version of (1) and (2) with eddy viscosity $K_{0}(>K)$,

$$
\begin{aligned}
& 0=f v_{0}+K_{0} \frac{\mathrm{d}^{2} u_{0}}{\mathrm{~d} z^{2}}, \\
& 0=-f\left(u_{0}-u_{\mathrm{g}}\right)+K_{0} \frac{\mathrm{d}^{2} v_{0}}{\mathrm{~d} z^{2}} .
\end{aligned}
$$

Our interest in the jet dynamics is confined to its development stage, and will not extend to sunrise when the eddy viscosity would be expected to increase rapidly with the onset of daytime convective mixing. 
It is convenient to non-dimensionalize variables as

$$
\begin{aligned}
& U \equiv \frac{u}{u_{\mathrm{g}}}, \quad V \equiv \frac{v}{u_{\mathrm{g}}}, \quad T \equiv f t, \\
& Z \equiv z \sqrt{\frac{f}{K_{0}}}, \quad \varepsilon \equiv \frac{K}{K_{0}},
\end{aligned}
$$

in terms of which (1)-(6) reduce to the following nondimensional system:

$$
\begin{aligned}
& \frac{\partial U}{\partial T}=V+\varepsilon \frac{\partial^{2} U}{\partial Z^{2}}, \\
& \frac{\partial V}{\partial T}=1-U+\varepsilon \frac{\partial^{2} V}{\partial Z^{2}}, \\
& U(0, T)=0, \quad V(0, T)=0, \\
& \lim _{Z \rightarrow \infty} U(Z, T)=1, \quad \lim _{Z \rightarrow \infty} V(Z, T)=0, \\
& 0=V_{0}+\frac{\mathrm{d}^{2} U_{0}}{\mathrm{~d} Z^{2}}, \\
& 0=1-U_{0}+\frac{\mathrm{d}^{2} V_{0}}{\mathrm{~d} Z^{2}} .
\end{aligned}
$$

This non-dimensional problem has a single degree of freedom - the turbulence reduction parameter $\varepsilon$.

In terms of the new dependent variable $\Phi \equiv U-1+\mathrm{i} V$, (8)-(13) become

$$
\begin{aligned}
& \frac{\partial \Phi}{\partial T}=-\mathrm{i} \Phi+\varepsilon \frac{\partial^{2} \Phi}{\partial Z^{2}}, \\
& \Phi(0, T)=-1, \\
& \lim _{Z \rightarrow \infty} \Phi(Z, T)=0, \\
& 0=-\mathrm{i} \Phi_{0}+\frac{\mathrm{d}^{2} \Phi_{0}}{\mathrm{~d} Z^{2}} .
\end{aligned}
$$

The solution of (17) subject to boundary conditions (15) and (16) is

$$
\Phi_{0}=-\exp \left\{-\frac{(1+\mathrm{i})}{\sqrt{2}} Z\right\}
$$

which is the standard steady-state Ekman solution expressed in a non-dimensional form based on (7). We anticipate that the terminal state $(T \rightarrow \infty)$ of the initial-value problem consisting of (14)-(16) and (18) would be the standard steady-state Ekman solution with reduced value of eddy viscosity $K$, which in non-dimensional form would appear as

$$
\Phi(Z, \infty)=-\exp \left\{-\frac{(1+\mathrm{i})}{\sqrt{2 \varepsilon}} Z\right\}
$$

\section{Analytical solution}

The initial-value problem will be solved by the method of Laplace transforms (Doetsch, 1961). Taking the Laplace transform $L$ of (14)-(16), and making use of (18) yields

$$
\begin{aligned}
& \varepsilon \frac{\mathrm{d}^{2} F}{\mathrm{~d} Z^{2}}-(s+\mathrm{i}) F=\exp \left\{-\frac{(1+\mathrm{i})}{\sqrt{2}} Z\right\}, \\
& F(0)=-\frac{1}{s} \\
& \lim _{Z \rightarrow \infty} F(Z)=0,
\end{aligned}
$$

where

$$
F(Z)=L[\Phi(Z, T)]=\int_{0}^{\infty} \exp (-s T) \Phi(Z, T) \mathrm{d} T .
$$

The homogeneous solution of (20) is

$$
F_{\mathrm{h}}=A \exp \left(\sqrt{\frac{s+\mathrm{i}}{\varepsilon} Z}\right)+B \exp \left(-\sqrt{\frac{s+\mathrm{i}}{\varepsilon} Z}\right),
$$

where $A$ and $B$ are constants. Affixing this solution to a particular solution of (20) (one is readily found as $-\{s-\mathrm{i}(\varepsilon-1)\}^{-1}$ times the exponential term in (20)), we obtain the general solution

$$
\begin{array}{r}
F=-\frac{1}{s-\mathrm{i}(\varepsilon-1)} \exp \left\{-\frac{(1+\mathrm{i})}{\sqrt{2}} Z\right\} \\
+A \exp \left(\sqrt{\frac{s+\mathrm{i}}{\varepsilon}} Z\right)+B \exp \left(-\sqrt{\frac{s+\mathrm{i}}{\varepsilon}} Z\right) .
\end{array}
$$

It can be shown that if (22) is to be satisfied, $A$ must be zero. Application of (21) in (25) then yields $B=\mathrm{i}(\varepsilon-1) s^{-1}\{s-\mathrm{i}(\varepsilon-1)\}^{-1}$, and (25) becomes

$$
\begin{gathered}
F=-\frac{1}{s-\mathrm{i}(\varepsilon-1)} \exp \left\{-\frac{(1+\mathrm{i})}{\sqrt{2}} Z\right\} \\
+\frac{\mathrm{i}(\varepsilon-1)}{s\{s-\mathrm{i}(\varepsilon-1)\}} \exp \left(-\sqrt{\frac{s+\mathrm{i}}{\varepsilon} Z}\right) .
\end{gathered}
$$

We solve for $\Phi=L^{-1}(F)$ by evaluating the inverse Laplace transform $L^{-1}$ of (26), making use of similarity and shifting theorems, the convolution theorem, and tabulated results for the inverse transforms of $s^{-1},(s+a)^{-1}$, and $\exp (-a \sqrt{s})$ (Doetsch, 1961; Roberts and Kaufman, 1966). The inverse transform of the first term in (26) is

$$
\begin{aligned}
L^{-1} & {\left[-\frac{1}{s-\mathrm{i}(\varepsilon-1)} \exp \left\{-\frac{(1+\mathrm{i})}{\sqrt{2}} Z\right\}\right] } \\
& =-\exp \left\{-\frac{(1+\mathrm{i})}{\sqrt{2}} Z+\mathrm{i}(\varepsilon-1) T\right\} .
\end{aligned}
$$

For the second term we note that since

$$
L^{-1}\left[\frac{\mathrm{i}(\varepsilon-1)}{s\{s-\mathrm{i}(\varepsilon-1)\}}\right]=\exp \{-\mathrm{i}(1-\varepsilon) T\}-1
$$

and

$$
\begin{array}{r}
L^{-1}\left[\exp \left(-\sqrt{\frac{s+\mathrm{i}}{\varepsilon} Z}\right)\right]=\frac{Z}{2 \sqrt{\pi \varepsilon} T^{3 / 2}} \\
\times \exp \left(-\mathrm{i} T-\frac{Z^{2}}{4 \varepsilon T}\right),
\end{array}
$$

the convolution theorem yields

$$
\begin{aligned}
& L^{-1}\left[\frac{\mathrm{i}(\varepsilon-1)}{s\{s-\mathrm{i}(\varepsilon-1)\}} \exp \left(-\sqrt{\frac{s+\mathrm{i}}{\varepsilon} Z}\right)\right] \\
& =-\int_{0}^{T} \frac{Z}{2 \sqrt{\pi \varepsilon} \tau^{3 / 2}} \exp \left(-\mathrm{i} \tau-\frac{Z^{2}}{4 \varepsilon \tau}\right) \\
& \times[1-\exp \{-\mathrm{i}(1-\varepsilon)(T-\tau)\}] \mathrm{d} \tau .
\end{aligned}
$$


Combining (27) with (30) and rearranging terms in the resulting expression, we obtain the solution

$$
\begin{aligned}
& \Phi(Z, T)=-\exp \left\{-\frac{(1+\mathrm{i})}{\sqrt{2}} Z+\mathrm{i}(\varepsilon-1) T\right\} \\
& -\int_{0}^{T} \frac{Z}{2 \sqrt{\pi \varepsilon} \tau^{3 / 2}} \exp \left(-\mathrm{i} \tau-\frac{Z^{2}}{4 \varepsilon \tau}\right) \mathrm{d} \tau+\exp \{-\mathrm{i}(1-\varepsilon) T\} \\
& \int_{0}^{T} \frac{Z}{2 \sqrt{\pi \varepsilon} \tau^{3 / 2}} \exp \left(-\mathrm{i} \varepsilon \tau-\frac{Z^{2}}{4 \varepsilon \tau}\right) \mathrm{d} \tau .
\end{aligned}
$$

This solution is exact but not of closed form. It can be verified that as $T \rightarrow \infty$, (31) converges to (19), that is, the terminal state of the initial value problem is the steady state Ekman solution with reduced eddy viscosity.

Since we are mostly interested in the solution for small non-dimensional times (in midlatitudes during the summer, the time interval between sunset and pre-dawn is up to half of an inertial oscillation period, $T<\pi$ ), we anticipate that a convenient and computationally efficient form of the solution can be obtained by making Taylor expansions in time. Expanding $\exp (-\mathrm{i} \tau)$ and $\exp (-\mathrm{i} \varepsilon \tau)$ in the two integrands in (31) in Taylor series about $T=0$ yields

$$
\begin{aligned}
& \Phi(Z, T)=-\sum_{n=0}^{\infty} \frac{(-\mathrm{i})^{n}}{n !}\left[1-\varepsilon^{n} \exp \{-\mathrm{i}(1-\varepsilon) T\}\right] \\
& \times \int_{0}^{T} \frac{\tau^{n-3 / 2}}{2 \sqrt{\pi \varepsilon}} Z \exp \left(-\frac{Z^{2}}{4 \varepsilon \tau}\right) \mathrm{d} \tau \\
& -\exp \left\{-\frac{(1+\mathrm{i})}{\sqrt{2}} Z+\mathrm{i}(\varepsilon-1) T\right\}
\end{aligned}
$$

Changing the integration variable in (32) to $\xi \equiv$ $Z /(2 \sqrt{\varepsilon \tau})$, and using $(-\mathrm{i})^{n}=\exp (-\mathrm{i} n \pi / 2)$ yields

$$
\begin{aligned}
& \Phi(Z, T)=\sum_{n=0}^{\infty} \frac{I(Z, T ; n)}{n !} \\
& \quad \times\left\{\varepsilon^{n} \exp \left(-\mathrm{i}(1-\varepsilon) T-\mathrm{i} \frac{n \pi}{2}\right)-\exp \left(-\mathrm{i} \frac{n \pi}{2}\right)\right\} \\
& -\exp \left(-\frac{(1+\mathrm{i})}{\sqrt{2}} Z+\mathrm{i}(\varepsilon-1) T\right)
\end{aligned}
$$

where

$$
I(Z, T ; n) \equiv\left(\frac{Z}{2 \sqrt{\varepsilon}}\right)^{2 n} \frac{2}{\sqrt{\pi}} \int_{\frac{Z}{2 \sqrt{\varepsilon T}}}^{\infty} \xi^{-2 n} \exp \left(-\xi^{2}\right) \mathrm{d} \xi .
$$

Integrating (34) by parts yields a recursive solution for $I(Z, T ; n)$ involving the complementary error function $\operatorname{erfc}(\Xi) \equiv 2 \pi^{-1 / 2} \int_{\Xi}^{\infty} \exp \left(-\xi^{2}\right) \mathrm{d} \xi$ (Abramowitz and Stegun, 1964):

$$
I(Z, T ; n)= \begin{cases}\operatorname{erfc}\left(\frac{Z}{2 \sqrt{\varepsilon T}}\right), & n=0, \\ \frac{Z}{\sqrt{\pi \varepsilon}} \frac{T^{n-1 / 2}}{2 n-1} \exp \left(-\frac{Z^{2}}{4 \varepsilon T}\right) & \\ -\frac{Z^{2}}{2 \varepsilon} \frac{I(Z, T ; n-1)}{2 n-1}, & n=1,2,3 \ldots\end{cases}
$$

We thus obtain $U=1+\operatorname{Re}(\Phi)$ and $V=\operatorname{Im}(\Phi)$ as

$$
\begin{aligned}
U= & \sum_{n=0}^{\infty} \frac{I(Z, T ; n)}{n !}\left\{\varepsilon^{n} \cos \left((1-\varepsilon) T+\frac{n \pi}{2}\right)-\cos \left(\frac{n \pi}{2}\right)\right\} \\
& +1-\exp \left(-\frac{Z}{\sqrt{2}}\right) \cos \left(\frac{Z}{\sqrt{2}}+(1-\varepsilon) T\right) \\
V= & \sum_{n=0}^{\infty} \frac{I(Z, T ; n)}{n !}\left\{\sin \left(\frac{n \pi}{2}\right)-\varepsilon^{n} \sin \left((1-\varepsilon) T+\frac{n \pi}{2}\right)\right\} \\
& +\exp \left(-\frac{Z}{\sqrt{2}}\right) \sin \left(\frac{Z}{\sqrt{2}}+(1-\varepsilon) T\right)
\end{aligned}
$$

where $I(Z, T ; n)$ is given by $(35)$.

Estimates of eddy viscosities in the daytime convective atmospheric boundary layer generally range from $\sim 10 \mathrm{~m}^{2} \mathrm{~s}^{-1}$ to several hundreds of $\mathrm{m}^{2} \mathrm{~s}^{-1}$ (e.g. Yamada and Mellor, 1975; Tombrou et al., 2007; Dandou et al., 2009). In contrast, eddy viscosities in the stable nocturnal boundary layer are much smaller, typically taking on values between $0.01 \mathrm{~m}^{2} \mathrm{~s}^{-1}$ and $1 \mathrm{~m}^{2} \mathrm{~s}^{-1}$ (e.g. Yamada and Mellor, 1975; Etling, 1987; Sharan and Gopalakrishnan, 1997; Krishna et al., 2003; Mahrt and Vickers, 2005; Cuxart and Jiménez, 2007; Dandou et al., 2009). Accordingly, we consider turbulence reduction parameters $\varepsilon$ ranging from 0.0001 to 0.1 . Numerical evaluation of (35)-(37) for that range shows that the full solution is well captured by just a few terms in the series for times up to half an inertial period and for heights up to the top of the computational domain $(Z=8$, which is far above the jet maximum). Changes in $U$ and $V$ are generally much less than $1 \%$ when the calculations are truncated at $n=9$ instead of $n=10$.

The evolution of the $U$ and $V$ profiles between sunset and roughly the time the jet attains its peak strength, approximately half the inertial oscillation period, is shown in Figure 2 for $\varepsilon=0.1$ and $\varepsilon=0.01$. The profiles for $\varepsilon=0.001$ and $\varepsilon=0.0001$ are not shown as they are quite similar to those for $\varepsilon=0.01$ but with the peak wind speed slightly larger and located even closer to the ground. Figure 2 reveals an accelerating flow at low levels, with peak wind speeds becoming supergeostrophic. The corresponding wind hodographs plotted as functions of time at any height from the top of the flow domain down to the location of the jet maximum are nearly half-circles (not shown), suggesting that the flow is effectively inviscid throughout that region. Viscous effects are confined to the very shallow layer on the underside of the jet. Figure 2 shows that the more drastic reduction in turbulent mixing $(\varepsilon=0.01)$ is associated with greater jet wind speeds. Moreover, the jet maximum is located closer to the ground for this case. These results are consistent with intuitive expectations about the solution behaviour: the greater the reduction in the ambient turbulence level (smaller $\varepsilon$ ), the larger the depth over which the flow is effectively inviscid (frictional effects become noticeable only very close to the ground). The reduced altitude at which frictional stresses first become important means that air parcels with greater initial ageostrophic wind speed can participate in the effectively inviscid inertial oscillation.

The wind component along the geostrophic wind direction ( $U$ component in Figure 2$)$ takes on the distinctive jet-like shape characteristic of observed low-level jets (e.g. Figs. 4 and 6 of Blackadar, 1957; Fig. 1 of Thorpe and Guymer, 1977; Fig. 4 of Parish et al., 1988; Fig. 5 of 

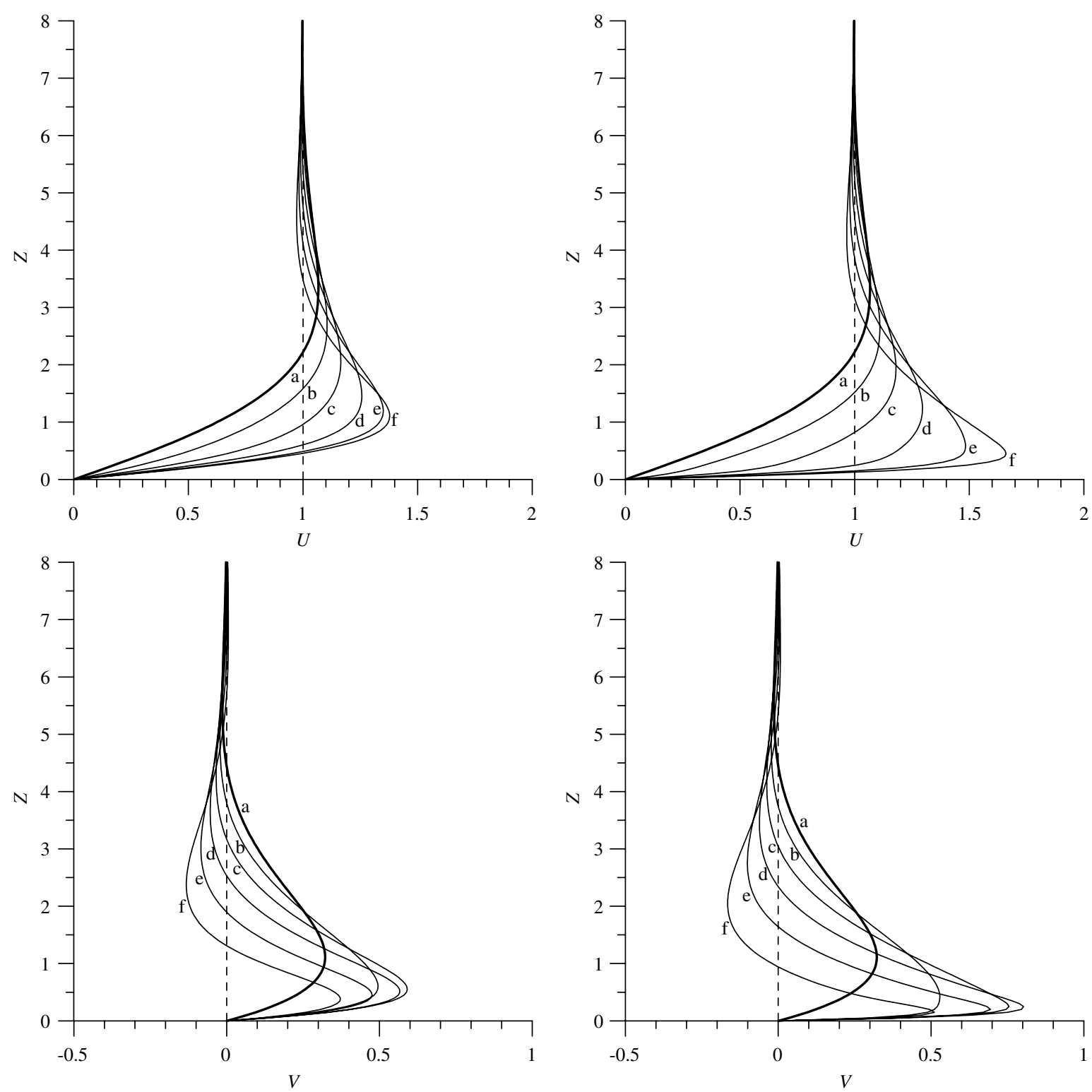

Figure 2. Evolution of vertical profiles of $U, V$ for $\varepsilon=0.1$ (left panels) and $\varepsilon=0.01$ (right panels). Curves a, b, c, d, e, f correspond to times $T=0,0.5$, $1,1.5,2,2.5$, respectively. Vertical dashed lines denote geostrophic wind components. All quantities are non-dimensional.

Zhong et al., 1996; Fig. 6 of Whiteman et al., 1997), with peak speeds exceeding geostrophic values by $\sim 70 \%$. This latter value is typical of many low-level jets, but is much less than the several hundred per cent values reported for the strongest cases (e.g. Hoecker, 1963; Bonner, 1968; Brook, 1985). Although these results are in qualitatively good agreement with some observations, one should be cautioned that some of the good agreement might be fortuitous. Firstly, as has already been mentioned, the notion of a constant eddy viscosity is rather tenuous. Indeed, an analysis of LES statistics from a low-level jet simulation (Cuxart and Jiménez, 2007) revealed a two-layer structure to the computed eddy viscosity with a minimum value near the wind maximum. Secondly, since observations of boundary layers under unstable or near-neutral conditions indicate that real wind hodographs (spirals) are typically flatter than their idealized constant eddy viscosity (Ekman) counterparts, some of the good agreement could be an artefact of the chosen Ekman framework.

Another notable feature of the analytical solution is the lowering of the height of the wind maximum. A descent of the wind maximum during the first half of the night is prominent in some numerical simulations of nocturnal jets over flat terrain without an imposed thermal wind, for example, the one-dimensional planetary boundary layer simulations of Delage (1974, Fig. 5), Brook (1985, Fig. 3) and Beyrich and Klose (1988, Figs. 3 and 4), and the LES experiments of Saiki et al. (2000, Fig. 13) and Kumar et al. (2006, Fig. 5). This feature is also evident to various extents in some observational datasets (e.g. Fig. 4 of Gifford, 1952; Table VI of Bonner, 1968; Fig. 10 of Mahrt et al., 1979; Fig. 1a,b of Arya, 1981; Fig. 7 of Beyrich and Weill, 1993; Fig. 9 of Mitchell et al., 1995; Fig. 2 of Beyrich et al., 1997). However, the Yamada and Mellor (1975) and Basu et al. (2008) numerical simulations of the boundary layer in the Wangara field experiment produced jets with wind maxima that were relatively constant throughout the night, in agreement with the Wangara observations. The simulations in those studies were conducted over flat terrain but with an imposed thermal wind. Other low-level jet observations reveal heights of wind maxima that are steady or even increase during the first half of the night (e.g. Fig. 9 of 
Mahrt et al., 1979; Fig. 1c,d,e of Arya, 1981; Fig. 1 of Sisterson and Frenzen, 1978; Figs. 7 and 8 of Banta, 2008). An analysis of high-resolution Doppler lidar data from the CASES-99 field campaign in Kansas revealed large variability in the temporal behaviour of the height of the wind maximum (Banta et al., 2002). Since a descending wind maximum was a more robust feature of the numerical simulations over flat terrain without an imposed thermal wind than of the observations (which were frequently over gentle, but generally non-zero, terrain slopes, and subject to synoptic influences), we speculate that the tendency of the height of some observed wind maxima to increase with time may be a consequence of synoptic- or terrain-associated baroclinicity. Other aspects of low-level jet structure and climatology have also been attributed to baroclinicity (Holton, 1967; Bonner and Paegle, 1970; Shapiro and Fedorovich, 2009).

\section{Summary}

An exact analytical solution of the one-dimensional equations of motion is presented for the evolution of a nocturnal low-level jet over flat terrain. The theory is based on the inertial-oscillation scenario proposed by Blackadar (1957) in which a nocturnal jet develops as a response of the boundary layer to the sudden reduction of turbulent mixing near sunset. In our study, the rapid decrease in turbulent mixing is emulated by impulsively reducing the eddy viscosity coefficient from one spatially constant value to another. The transient problem is solved by the method of Laplace transforms. The solution indicates that greater reductions in the turbulent exchange are associated with more intense jets, and with jet maxima that are found closer to the ground. The shape and intensity of the wind profiles are in qualitative agreement with some observations. However, although the theory yields peak jet wind speeds that exceed the geostrophic values by $\sim 70 \%$ (which is consistent with many observations), the theory cannot explain observed cases where the peak winds are several hundreds of per cent of the geostrophic values. Synoptic- or terrain-associated baroclinicity may well be a factor in the development of these latter jets (Holton, 1967; Bonner and Paegle, 1970; Shapiro and Fedorovich, 2009). We plan to extend our current methodology to include this effect.

\section{Acknowledgements}

Discussions with Sean Arms, Petra Klein, David Stensrud and Bas van de Wiel are gratefully acknowledged. We also thank the reviewers for their helpful comments. This research was supported in part by grant ATM-0124068 from the United States National Science Foundation.

\section{References}

Abramowitz M, Stegun IA. 1964. Handbook of mathematical functions with formulas, graphs, and mathematical tables. National Bureau of Standards Applied Mathematics Series No. 55, US Dept. of Commerce: Washington, DC.

Arya SPS. 1981. Parameterizing the height of the stable atmospheric boundary layer. J. Appl. Meteorol. 20: 1192-1202.

Banta RM. 2008. Stable-boundary-layer regimes from the perspective of the low-level jet. Acta Geophys. 56: 58-87.

Banta RM, Newsom RK, Lundquist JK, Pichugina YL, Coulter RL, Mahrt L. 2002. Nocturnal low-level jet characteristics over Kansas during CASES-99. Boundary-Layer Meteorol. 105: 221-252.

Basu S, Vinuesa J-F, Swift A. 2008. Dynamic LES modeling of a diurnal cycle. J. Appl. Meteorol. Clim. 47: 1156-1174.
Beyrich F, Klose B. 1988. Some aspects of modelling low-level jets. Boundary-Layer Meteorol. 43: 1-14.

Beyrich F, Weill A. 1993. Some aspects of determining the stable boundary layer depth from sodar data. Boundary-Layer Meteorol. 63: 97-116.

Beyrich F, Kalass D, Weisensee U. 1997. Influence of the nocturnal lowlevel-jet on the vertical and mesoscale structure of the stable boundary layer as revealed from Doppler-sodar-observations. Pp 236-246 in Acoustic remote sensing applications, Singal SP (ed). Narosa Publishing House: New Delhi.

Blackadar AK. 1957. Boundary layer wind maxima and their significance for the growth of nocturnal inversions. Bull. Am. Meteorol. Soc. 38: 283-290.

Bonner WD. 1968. Climatology of the low level jet. Mon. Weather Rev. 96: $833-850$.

Bonner WD, Paegle J. 1970. Diurnal variations in boundary layer winds over the south-central United States in summer. Mon. Weather Rev. 98: 735-744.

Brook RR. 1985. The Koorin nocturnal low-level jet. Boundary-Layer Meteorol. 32: 133-154.

Buajitti K, Blackadar AK. 1957. Theoretical studies of diurnal windstructure variations in the planetary boundary layer. Q. J. R. Meteorol. Soc. 83: $486-500$.

Chereskin TK. 1995. Direct evidence for an Ekman balance in the California Current. J. Geophys. Res. 100(C9): 18261-18269.

Clarke RH. 1970. Observational studies in the atmospheric boundary layer. Q. J. R. Meteorol. Soc. 96: 91-114.

Cuxart J, Jiménez MA. 2007. Mixing processes in a nocturnal low-level jet: An LES study. J. Atmos. Sci. 64: 1666-1679.

Dandou A, Tombrou M, Schäfer K, Emeis S, Protonotariou AP, Bossioli E, Soulakellis N, Suppan P. 2009. A comparison between modelled and measured mixing-layer height over Munich. BoundaryLayer Meteorol. 131: 425-440.

Davies PA. 2000. Development and mechanisms of the nocturnal jet. Meteorol. Appl. 7: 239-246.

Defant F. 1949. Zur Theorie der Hangwinde, nebst Bemerkungen zur Theorie der Berg- und Talwinde. Arch. Meteorol. Geophys. Bioklim. A 1: $421-450$.

Delage Y. 1974. A numerical study of the nocturnal atmospheric boundary layer. Q. J. R. Meteorol. Soc. 100: 351-364.

Doetsch G. 1961. Guide to the applications of Laplace transforms. Van Nostrand: London.

Egger J. 1981. On the linear two-dimensional theory of thermally induced slope winds. Beitr. Phys. Atmos. 54: 465-481.

Ekman VW. 1905. On the influence of the Earth's rotation on ocean currents. Arkiv. Matematik. Astron. Fysik 2: 1-53.

Etling D. 1987. The planetary boundary layer. Pp 151-188 in LandoltBörnstein: New Series, Group V, Vol. 4, Meteorology, Subvol. C1, Climatology, Part 1. Springer-Verlag: New York.

Gifford FA. 1952. The breakdown of a low-level inversion studied by means of detailed soundings with a modified radiosonde. Bull. Am. Meteorol. Soc. 33: 373-379.

Hoecker WH Jr. 1963. Three southerly low-level jet systems delineated by the Weather Bureau special pibal network of 1961. Mon. Weather Rev. 91: 573-582.

Holton JR. 1967. The diurnal boundary layer wind oscillation above sloping terrain. Tellus 19: 199-205.

Hong S-Y, Noh Y, Dudhia J. 2006. A new vertical diffusion package with an explicit treatment of entrainment processes. Mon. Weather Rev. 134: $2318-2341$.

Houghton JT. 1977. The physics of atmospheres. Cambridge University Press.

Karipot A, Leclerc MY, Zhang G. 2009. Characteristics of nocturnal low-level jets observed in the north Florida area. Mon. Weather Rev. 137: 2605-2621.

Kondo H. 1984. The difference of the slope wind between day and night. J. Meteorol. Soc. Jpn 62: 224-233.

Krishna TBPSRV, Sharan M, Gopalakrishnan SG, Aditi. 2003. Mean structure of the nocturnal boundary layer under strong and weak wind conditions: EPRI case study. J. Appl. Meteorol. 42: 952-969.

Kumar V, Kleissl J, Meneveau C, Parlange MB. 2006. Large-eddy simulation of a diurnal cycle of the atmospheric boundary layer: Atmospheric stability and scaling issues. Water Resour. Res. 42: W06D09, DOI:10.1029/2005WR004651.

Lettau H. 1983. Thoughts on priorities in boundary-layer research. Boundary-Layer Meteorol. 25: 429-432.

Mahrt L, Vickers D. 2005. Extremely weak mixing in stable conditions. Boundary-Layer Meteorol. 119: 19-39.

Mahrt L, Heald RC, Lenschow DH, Stankov BB, Troen IB. 1979. An observational study of the structure of the nocturnal boundary layer. Boundary-Layer Meteorol. 17: 247-264. 
Mitchell MJ, Arritt RW, Labas K. 1995. A climatology of the warm season Great Plains low-level jet using wind profiler observations. Weather and Forecasting 10: 576-591.

Oerlemans J. 1998. The atmospheric boundary layer over melting glaciers. Pp 129-153 in Clear and cloudy boundary layers, Holtslag AAM, Duynkerke PG (eds). R. Netherlands Acad. of Arts and Sci.: Amsterdam.

Papadopoulos KH, Helmis CG, Soilemes AT, Kalogiros J, Papageorgas PG, Asimakopoulos DN. 1997. The structure of katabatic flows down a simple slope. Q. J. R. Meteorol. Soc. 123: 1581-1601.

Parish TR, Rodi AR, Clark RD. 1988. A case study of the summertime Great Plains low level jet. Mon. Weather Rev. 116: 94-105.

Pedlosky J. 1987. Geophysical fluid dynamics, 2nd edition. SpringerVerlag: New York.

Price JF, Weller RA, Schudlich RR. 1987. Wind-driven ocean currents and Ekman transport. Science 238: 1534-1538.

Ralph EA, Niiler PP. 1999. Wind-driven currents in the tropical Pacific. J. Phys. Oceanogr. 29: 2121-2129.

Roberts GE, Kaufman H. 1966. Table of Laplace transforms. W. B. Saunders: Phildadelphia.

Saiki EM, Moeng C-H, Sullivan PP. 2000. Large-eddy simulation of the stably stratified planetary boundary layer. Boundary-Layer Meteorol. 95: $1-30$.

Saulo AC, Seluchi ME, Nicolini M. 2004. A case study of a Chaco low-level jet event. Mon. Weather Rev. 132: 2669-2683.

Shapiro A, Fedorovich E. 2009. Nocturnal low-level jet over a shallow slope. Acta Geophys. 57: 950-980.

Sharan M, Gopalakrishnan SG. 1997. Comparative evaluation of eddy exchange coefficients for strong and weak wind stable boundary layer modeling. J. Appl. Meteorol. 36: 545-559.

Sheih CM. 1972. A theoretical study of the diurnal wind variations in the planetary boundary layer. J. Atmos. Sci. 29: 995-998.

Singh MP, McNider RT, Lin JT. 1993. An analytical study of diurnal wind-structure variations in the boundary layer and the low-level nocturnal jet. Boundary-Layer Meteorol. 63: 397-423.

Sisterson DL, Frenzen P. 1978. Nocturnal boundary-layer wind maxima and the problem of wind power assessment. Environ. Sci. Technol. 12: $218-221$.

Sládkovič R, Kanter H-J. 1977. Low-level jet in the Bavarian pre-alpine region. Arch. Meteorol. Geophys. Bioklim. Ser. A 25: 343-355.

Song J, Liao K, Coulter RL, Lesht BM. 2005. Climatology of the lowlevel jet at the Southern Great Plains Atmospheric Boundary Layer Experiments site. J. Appl. Meteorol. 44: 1593-1606.
Sorbjan Z. 1989. Structure of the atmospheric boundary layer. Prentice Hall: Englewood Cliffs, New Jersey.

Staley DO. 1956. The diurnal temperature wave for bounded eddy conductivity. J. Meteorol. 13: 13-20.

Stensrud DJ. 1996. Importance of low-level jets to climate: A review. J. Climate 9: 1698-1711.

Stull RB. 1988. An introduction to boundary layer meteorology. Kluwer Academic Publishers: Dordrecht

Sun W-Y, Orlanski I. 1981. Large mesoscale convection and sea breeze circulation. Part I: Linear stability analysis. J. Atmos. Sci. 38: $1675-1693$.

Thorpe AJ, Guymer TH. 1977. The nocturnal jet. Q. J. R. Meteorol. Soc. 103: 633-653.

Tombrou M, Dandou A, Helmis C, Akylas E, Angelopoulos G, Flocas H, Assimakopoulos V, Soulakellis N. 2007. Model evaluation of the atmospheric boundary layer and mixed-layer evolution. Boundary Layer Meteorol. 124: 61-79.

Walsh JE. 1974. Sea breeze theory and applications. J. Atmos. Sci. 31: 2012-2026.

Walters CK, Winkler JA, Shadbolt RP, van Ravensway J, Bierly GD. 2008. A long-term climatology of southerly and northerly low-level jets for the central United States. Ann. Assoc. Amer. Geog. 98: 521-552.

Whiteman CD, Bian X, Zhong S. 1997. Low-level jet climatology from enhanced rawinsonde observations at a site in the southern Great Plains. J. Appl. Meteorol. 36: 1363-1376.

Wippermann F. 1973. Numerical study on the effects controlling the low-level jet. Beitr. Phys. Atmos. 46: 137-154.

Yamada T, Mellor G. 1975. A simulation of the Wangara atmospheric boundary layer data. J. Atmos. Sci. 32: 2309-2329.

Zemba J, Friehe CA. 1987. The marine atmospheric boundary layer jet in the Coastal Ocean Dynamics Experiment. J. Geophys. Res. 92(C2): 1489-1496.

Zhang D-L, Zhang S, Weaver SJ. 2006. Low-level jets over the midAtlantic states: Warm-season climatology and a case study. J. Appl. Meteorol. Clim. 45: 194-209.

Zhong S, Fast JD, Bian X. 1996. A case study of the Great Plains low-level jet using wind profiler network data and a high-resolution mesoscale model. Mon. Weather Rev. 124: 785-806. 